Supporting Information

\title{
Control of Asymmetric Scattering Behavior of Plasmonic Nanoparticle Ensembles
}

\author{
Koichiro Saito and Tetsu Tatsuma* \\ Institute of Industrial Science, The University of Tokyo, 4-6-1 Komaba, Meguro-ku, \\ Tokyo 153-8505, Japan
}


Supporting Movies (Web-Enhanced Objects)

\section{Movie 1.}

Asymmetric scattering of $\mathrm{S} \mathrm{SiO}_{2}$ film with embedded $\mathrm{Au}$ nanorods (AuNR, width $=33 \mathrm{~nm}$, length $=70 \mathrm{~nm})$ and $\mathrm{Ag}$ nanospheres $(\mathrm{AgNS}$, diameter $=60 \mathrm{~nm})$ coated on a $\mathrm{TiO}_{2}$ film [glass $\left./ \mathrm{TiO}_{2}(40 \mathrm{~nm}) / \mathrm{AgNS} / \mathrm{SiO}_{2}(120 \mathrm{~nm}) / \mathrm{AuNR} / \mathrm{SiO}_{2}(120 \mathrm{~nm})\right]$. The focus is on the sample initially, then is moved to the background image.

\section{Movie 2.}

Asymmetric scattering of $\mathrm{a} \mathrm{SiO}_{2}$ film with embedded $\mathrm{Au}$ nanorods (AuNR, width $=33 \mathrm{~nm}$, length $=70 \mathrm{~nm})$ and $\mathrm{Ag}$ nanospheres $(\mathrm{AgNS}$, diameter $=40 \mathrm{~nm})$ coated on a $\mathrm{TiO}_{2}$ film [glass/ $\left.\mathrm{TiO}_{2}(40 \mathrm{~nm}) / \mathrm{AuNR} / \mathrm{SiO}_{2}(70 \mathrm{~nm}) / \mathrm{AgNS} / \mathrm{SiO}_{2}(210 \mathrm{~nm})\right]$. The focus is on the sample initially, then is moved to the background image. 